\title{
A dynamic case definition is warranted for adequate notification in an extended epidemic setting: the Dutch Q fever outbreak 2007-2009 as exemplar
}

G Jaramillo-Gutierrez 1,2,3, M C Wegdam-Blans (m.wegdam@pamm.nl)3,4, R ter Schegget ${ }^{5}$, J M Korbeeck ${ }^{4}$, R van Aken4, H A Bijlmer ${ }^{1}$, J H Tjhie ${ }^{4}$, M P Koopmans ${ }^{1}$

1. Centre for Infectious Disease Control, National Institute for Public Health and the Environment (RIVM), Bilthoven, the Netherlands

2. European Programme for Public Health Microbiology Training (EUPHEM), European Centre for Disease Prevention and Control (ECDC), Stockholm, Sweden

3. These authors contributed equally

4. Department of Medical Microbiology, Laboratory for Pathology and Medical Microbiology (PAMM), Veldhoven, the Netherlands

5. Municipal Health Service Brabant-South-East, Helmond, the Netherlands

Citation style for this article:

Jaramillo-Gutierrez G, Wegdam-Blans MC, ter Schegget R, Korbeeck JM, van Aken R, Bijlmer HA, Tjhie JH, Koopmans MP. A dynamic case definition is warranted for adequate notification in an extended epidemic setting: the Dutch Q fever outbreak 2007-2009 as exemplar. Euro Surveill. 2013;18(41):pii=20606. Available online: http://www.eurosurveillance.org/ViewArticle.aspx?Articleld=20606

Article submitted on 07 December 2012 / published on 10 October 2013

Q fever is a notifiable disease in the Netherlands: laboratories are obliged to notify possible cases to the Municipal Health Services. These services then try to reconfirm cases with additional clinical and epidemiological data and provide anonymised reports to the national case register of notifiable diseases. Since the start of the 2007-2009 Dutch Q fever outbreak, notification rules remained unchanged, despite new laboratory insights and altered epidemiology. In this study, we retrospectively analysed how these changes influenced the proportion of laboratory-defined acute $Q$ fever cases (confirmed, probable and possible) that were included in the national case register, during (2009) and after the outbreak (2010 and 2011). The number of laboratory-defined cases notified to the Municipal Health Services was 377 in2009, 96 in 2010 and 50 in 2011. Of these, 186 (49.3\%) in 2009, 12 $(12.5 \%)$ in 2010 and $9(18.0 \%)$ in 2011 were confirmed as acute infection by laboratory interpretation. The proportion of laboratory-defined acute $Q$ fever cases that was reconfirmed by the Municipal Health Services and that were included in the national case register decreased from $90 \%$ in 2009 , to $22 \%$ and $24 \%$ in 2010 and 2011, respectively. The decrease was observed in all categories of cases, including those considered to be confirmed by laboratory criteria. Continued use of a pre-outbreak case definition led to over-reporting of cases to the Municipal Health Services in the post-epidemic years. Therefore we recommend dynamic laboratory notification rules, by reviewing case definitions periodically in an ongoing epidemic, as in the Dutch $Q$ fever outbreak.

\section{Introduction}

$Q$ fever is a zoonotic disease and human infections result mainly from inhalation of Coxiella burnetii-contaminated aerosols [1-3]. Domestic ruminants are the main reservoir of the causative pathogen. Infected animals can shed $C$. burnetii in their milk or faecal excretions. Infections in humans can occur after contact with infected animals or contaminated dust [1-3]. Acute $Q$ fever is mostly self-limiting, but antibiotic treatment can reduce the duration of symptoms [1-3]. Early detection of $\mathrm{Q}$ fever cases is hampered by the atypical polymorphic presentation of symptoms, ranging from asymptomatic to influenza-like illness, fever and pneumonia in acute infections. Therefore under-reporting is quite substantial, especially in the beginning of an outbreak or if there is no knowledge of possible animal contact history [1-3]. The incubation period for C. burnetii infections is generally 9-40 days. About $1-5 \%$ of all $Q$ fever cases may progress to chronic infection, often leading to a life-threatening endocarditis or vascular infection $[1,2]$.

Q fever has been a notifiable disease since 1976 in the Netherlands. The head of diagnostic microbiology laboratories and the treating physicians are obliged to notify the local public health authorities (the Municipal Health Services, MHS) of possible cases [4]. In accordance with the Public Health Act, the MHS provides anonymised reports to the national case register (NCR) of notifiable diseases [4]. The decision of the MHS to report acute $Q$ fever cases to the NCR is based on the combination of laboratory supporting evidence together with clinical information. Soon after a patient is notified to the MHS, clinical information is acquired by a MHS infectious disease specialist by consulting 
Epidemic curve of 2007-2009 regional Q fever outbreak and post-outbreak years (2010-2011) combined with test activity by time period, south-east Brabant, the Netherlands $(n=622)^{\mathrm{a}, \mathrm{b}}$

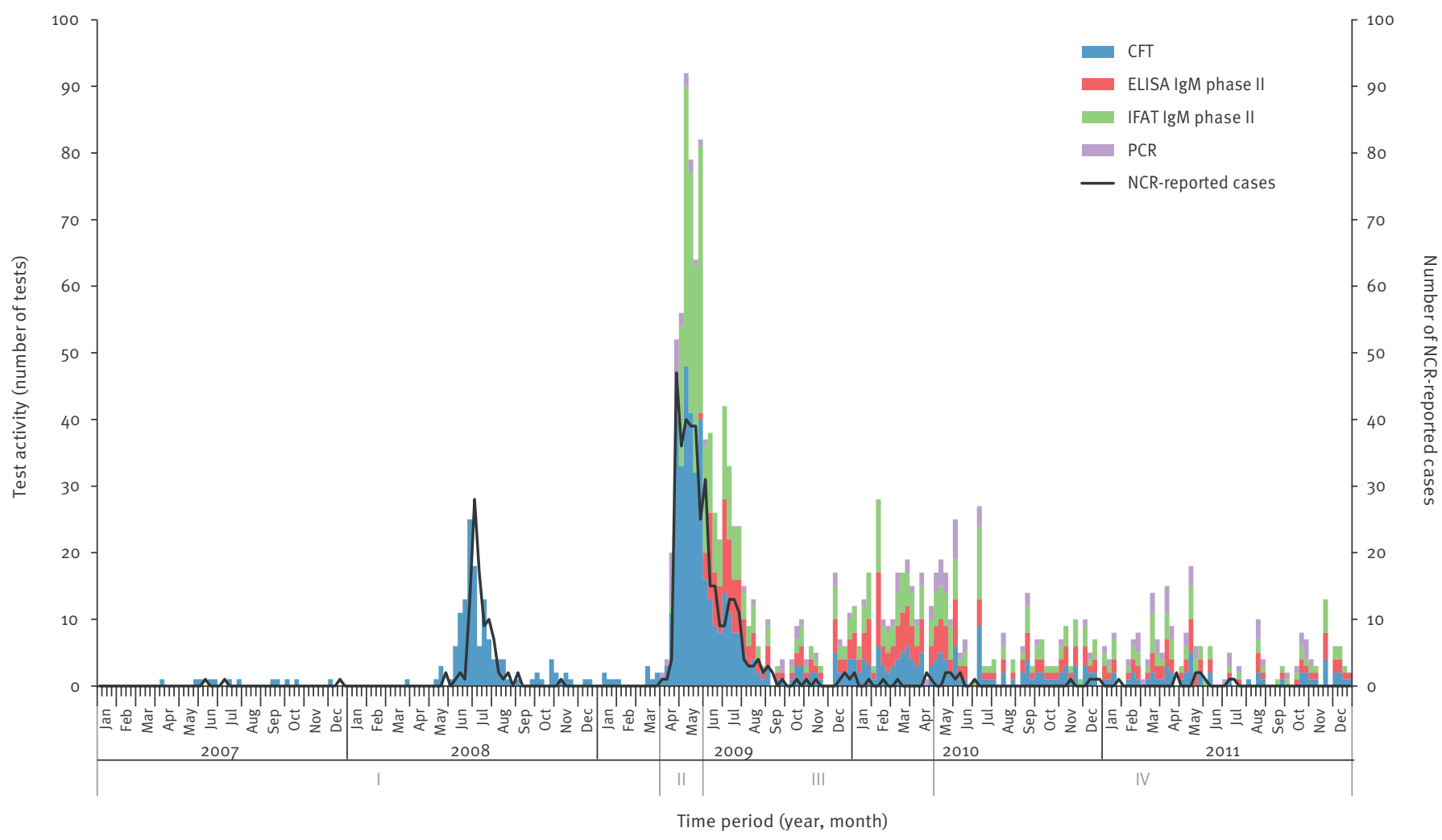

CFT: complement fixation test, ELISA: enzyme-linked immunosorbent assay; IFAT: indirect fluorescent antibody test; NCR: national case register; PCR: polymerase chain reaction.

Time periods: before April 2009 (I), between April and May 2009 (II), between June 2009 and April 2010 (III), from May2010 to December 2011 (IV).

Each bar represents all tests performed at that time for notified patients.

a In 2007, $n=3$; in 2008, $n=96$; in 2009-2011, $n=523$.

b Data from Laboratory for Pathology and Medical Microbiology (PAMM), Veldhoven, the Netherlands, including occasional PCR results before April 2010 from an external laboratory.

the physician and by questioning the patient using a questionnaire. Whenever a patient presents with at least one of three parameters (fever, pneumonia or hepatitis), a case is reconfirmed and reported to the NCR.

Q fever diagnosis is based on DNA detection by polymerase chain reaction $(P C R)$ and serology $[5,6]$. The presence or absence of four different types of antibodies determines different stages of the infection. IgM and IgG antibodies against $C$. burnetii phase II antigen have been associated with early stages of illness, whereas IgM phase I and especially IgG phase I antibodies are indicative of ongoing (chronic) Q fever [2].

Various serological tests are available for acute $Q$ fever, including indirect fluorescent antibody tests
(IFATs), enzyme-linked immunosorbent assays (ELISAs) and complement fixation tests (CFTs). Recently, it was shown that the performances of these tests, in terms of confirming acute $Q$ fever, were comparable [7]. In our laboratory in the south-east of Brabant (Laboratory for Pathology and Medical Microbiology (PAMM), Veldhoven), all three serological tests listed, together with $P C R$, are used for the diagnosis of acute $Q$ fever. An algorithm was developed that supports the choice of PCR and/or serology based on the time between the first day of symptom onset and serum collection [8].

The south of the Netherlands experienced a largescale outbreak of $Q$ fever over three consecutive years (2007-2009), with the highest peak in 2009 [9,10]. At the beginning of the outbreak, a national case definition, including laboratory diagnostics, was established 
and used for mandatory notification [11]. This case definition was not modified during the outbreak, and was based on the knowledge available in the Netherlands about $Q$ fever diagnostics at that time, which was quite limited. As this outbreak constitutes one of the largest outbreaks ever recorded, with more than 4,000 acute $Q$ fever cases notified, comparative laboratory-based studies yielded new insights on diagnostic markers for acute $Q$ fever. Most importantly, it was shown that the serological response after infection is long-lasting and that IgG phase II as well as IgM phase II antibodies are detected in more than half of acute $Q$ fever cases a year after symptom onset [7]. This implies that the serological diagnosis of acute $Q$ fever based on a single serum sample - which was part of the case definition - can be inaccurate.

In the study presented here, we evaluated the specificity of the laboratory-defined acute $Q$ fever cases during (2009) and after the epidemic (2010 and 2011). We also wanted to illustrate that interactions between the laboratory, physician and public health staff become more complex during an ongoing epidemic. Adaptation of the interpretation of laboratory results is warranted more and more in such a situation, especially when the laboratory techniques change over time.

\section{Methods}

\section{Case definition}

The current Dutch case definition for acute $Q$ fever, based on clinical parameters and laboratory results, was used [11], i.e. any personwho presents with at least one of three symptoms: fever, pneumonia and/ or hepatitis, combined with positive laboratory results from any of the following three tests:

- detection of $C$. burnetii DNA in serum of patients without signs of chronic $Q$ fever;

- serum conversion or fourfold rise in IgG-specific phase II antibody titre by IFAT or CFT;

- single serum detection of IgM phase II antibodiesby IFAT or ELISA with or without IgG phase II antibodies.

\section{Diagnostic tests and outcomes}

During the study period (January 2009 to December 2011), new tests were implemented in our laboratory, situated in the south-east of the province of Brabant. The evolution of the outbreak challenged the diagnostic capacities in the affected regions (Figure). Firstly, ELISA IgM phase II was introduced, to improve through put time by automation. Secondly, IFAT was introduced, to improve specificity. Finally, PCR was introduced, to improve early diagnosis (Table 1). A detailed description of the different test methods has been published [9]. Due to the introduction of new techniques throughout the years, seven different outcomes lead to case notification to the MHS (Table 2). On the basis of the laboratory criteria, whenever PCR was positive or a fourfold rise in IgG phase II antibodies was measured using CFT (outcomes 1 and 2, Table 2), the patient
TABLE 1

Test methods used during (2009) and after (2010-2011) the 2007-2009 Q fever outbreak, the Netherlands ${ }^{a}$

\begin{tabular}{|c|c|c|}
\hline Time period & $\begin{array}{l}\text { Duration of } \\
\text { symptoms }^{b}\end{array}$ & Methods \\
\hline $\begin{array}{l}\text { I } \\
\text { January } 2009- \\
\text { March } 2009\end{array}$ & Not applicable & $\begin{array}{l}\text { CFT } \\
P^{c} R^{c}\end{array}$ \\
\hline $\begin{array}{l}\text { II } \\
\text { April 2009- } \\
\text { May } 2009\end{array}$ & Not applicable & $\begin{array}{c}\text { IFAT IgM phase II } \\
\text { CFT } \\
\text { PCR }\end{array}$ \\
\hline $\begin{array}{l}\text { III } \\
\text { June 2009- } \\
\text { April } 2010\end{array}$ & Not applicable & $\begin{array}{c}\text { ELISA IgM phase II } \\
\text { confirmed by IFAT } \\
\text { IgM phase II } \\
\text { CFT } \\
\text { PCR }\end{array}$ \\
\hline \multirow[t]{2}{*}{$\begin{array}{l}\text { IV } \\
\text { April 2010- } \\
\text { December } 2011\end{array}$} & $\begin{array}{c}\geq 21 \text { days or } \\
\text { unknown }\end{array}$ & $\begin{array}{c}\text { ELISA IgM phase II } \\
\text { confirmed by IFAT } \\
\text { IgM phase } \text { II }^{\mathrm{d}} \\
\text { CFT }\end{array}$ \\
\hline & «21 days & $P C R^{e}$ \\
\hline
\end{tabular}

CFT: complement fixation test; ELISA: enzyme-linked immunosorbent assay; IFAT: indirect fluorescent antibody test; PCR: polymerase chain reaction.

Data from Laboratory for Pathology and Medical Microbiology (PAMM), Veldhoven.

b An algorithm, based on the time between the first day of symptom onset and serum collection, comprises the use of PCR and serology tests. For patients sampled within the first two weeks of illness, it is recommended to perform PCR. For patients having first contact with a physician later than two weeks postsymptom onset or for patients for whom the date of symptom onset is not known, serology is recommended as the initial test. Before April 2010, PCR was occasionally performed in an external laboratory. Whenever PCR was negative, IgM phase II testing was performed (ELISA IgM phase II confirmed by IFAT IgM phase II).

ELISA IgM phase II positive samples were confirmed using IFAT.

From April 2010, PCR was implemented in routine Q fever testing in our laboratory. Whenever PCR was negative, IgM phase II testing was performed (ELISA IgM phase II confirmed by IFAT IgM phase II).

was considered to be a confirmed acute $Q$ fever case. Whenever IgG phase II antibodies using CFT and IgM phase II antibodies using ELISA and/or IFAT were measured in a single serum sample, the patient was considered a probable case of acute $Q$ fever (outcomes 3, 4 and 5). When only IgM phase II antibodies using ELISA and IFAT were detected, cases were considered to be possible acute cases (outcomes 6 and 7 ).

\section{Reporting to the national case register}

The notification system in the Netherlands works like a funnel: firstly, all laboratory-defined acute $Q$ fever patients (confirmed, probable and possible) were notified by the laboratory to the MHS. Secondly, the MHS infectious disease specialist reviewed all cases. If the case also met the clinical criteria, notification was reconfirmed and reported to the NCR. If the case did not meet these criteria, it was registered as not notifiable. 
Laboratory-defined acute Q fever patients based on test methods used, the Netherlands, 2007-2011

\begin{tabular}{|c|c|c|c|c|c|c|}
\hline $\begin{array}{c}\text { PCR } \\
\text { positive }\end{array}$ & $\begin{array}{c}\text { CFT } \\
\text { IgG } \\
\text { phase II } \\
\text { increase }^{a}\end{array}$ & $\begin{array}{c}\text { CFT } \\
\text { IgG } \\
\text { phase II } \\
\text { positive }^{b}\end{array}$ & $\begin{array}{c}\text { ELISA } \\
\text { IgM } \\
\text { phase II } \\
\text { positive }\end{array}$ & $\begin{array}{c}\text { IFAT } \\
\text { IgM } \\
\text { phase II } \\
\text { positive }^{c}\end{array}$ & Outcome & Laboratory interpretation \\
\hline \multirow[t]{7}{*}{$x$} & & & & & 1 & Confirmed case \\
\hline & $x$ & & & & $2^{d}$ & Confirmed case \\
\hline & & $x$ & $x$ & $x$ & 3 & Probable case \\
\hline & & $x$ & & $x$ & 4 & Probable case \\
\hline & & $x$ & & & 5 & Probable case \\
\hline & & & $x$ & $x$ & 6 & Possible case \\
\hline & & & & $x$ & 7 & Possible case \\
\hline
\end{tabular}

CFT: complement fixation test; ELISA: enzyme-linked immunosorbent assay; IFAT: indirect fluorescent antibody test; PCR: polymerase chain reaction.

IgG phase II increase defined as a fourfold titre increase or seroconversion, measured by CFT.

b Cut-off titre $>1: 4$.

Cut-off titre $\geq 1: 32$.

A serum pair for one episode of Q fever was defined whenever these sera were collected within 90 days.

\section{Data analysis}

The dataset with the reconfirmed and not-notifiable acute $Q$ fever cases from MHS Brabant-South-East was merged with the laboratory test results, based on the patients' six-digit postal code and date of birth. After merging, retrospective analysis of the acute $Q$ fever cases during 1 January 2009 to 31 December 2011 was conducted. Descriptive analysis included age and sex. Cases were grouped according to the laboratory interpretations (1-7) and reviewed to assess what proportion was finally included in the NCR.

Statistical analysis included computations of laboratory-outcome frequencies per year and the percentage of reconfirmed notified and not-notifiable cases per year. Significance in these groups computed using one-sided Mann-Whitney test and Fisher's exact test, respectively.

\section{Results}

\section{Patients' characteristics}

From 1 January 2009 to 31 December 2011, 658 Q fever patients were reported by laboratories in south-east Brabant to the MHS, of which 523 were from our laboratory. The remaining 135 patients were reported by other laboratories in the region and were not included in the analysis. The mean age of the 523 patients was 49 years (standard deviation (SD): 16), and 320 (61.2\%) were male.
Diagnostic tests and outcomes

Of the 523 laboratory-defined cases notified to the MHS by our laboratory, 377 occurred in 2009, 96 in 2010 and 50 in 2011. During these three years, the distribution of laboratory outcomes changed substantially (Table 3): in $2009,49.3 \%(186 / 377)$ of the patients in the MHS database were considered confirmed cases, mainly based on IgG seroconversion. Although PCR was indicated for most of the cases, it was seldom performed because this technique was not implemented in our laboratory before April 2010. Only 17.2\% (65/377) of the notified patients in 2009 were considered possible cases, based on single IgM phase II response. The distribution changed over the years, with far fewer patients belonging to the confirmed category based on laboratory criteria in 2010 and 2011. The category of patients considered to be least certain (possible), based on laboratory criteria, increased over time, constituting almost half of the patients diagnosed in 2011. These differences in distribution were significant when comparing 2010 vs 2011 and 2009 vs 2011 (Table 3).

\section{Reporting to the national case register}

In 2009, all laboratory-confirmed cases, except two, were reconfirmed by MHS and reported to the NCR (184/186) (Table 4). In 2010 and 2011, the proportion of reconfirmed cases dropped: only 7/12 and 4/9 of the cases considered to be confirmed by laboratory criteria in 2010 and 2011 respectively were reported to the NCR. Interestingly, six of the 10 cases reported in 2010 and 2011 not reconfirmed were PCR positive in the 
Laboratory-defined Q fever cases notified to the Municipal Health Service of south-east Brabant, the Netherlands, 2009-2011 $(n=523)$

\begin{tabular}{|c|c|c|c|c|c|c|c|c|}
\hline \multirow{3}{*}{$\begin{array}{l}\text { Year } \\
\text { (number of } \\
\text { cases) }\end{array}$} & \multicolumn{3}{|c|}{$\begin{array}{c}\text { Confirmed cases } \\
n(\%)\end{array}$} & \multicolumn{2}{|c|}{$\begin{array}{c}\text { Probable cases } \\
\text { n (\%) }\end{array}$} & \multicolumn{2}{|c|}{$\begin{array}{c}\text { Possible cases } \\
\text { n (\%) }\end{array}$} & \multirow{3}{*}{$\begin{array}{l}\text { P value } \\
\text { between } \\
\text { years }\end{array}$} \\
\hline & \multicolumn{7}{|c|}{ Outcome } & \\
\hline & 1 & $2^{\mathrm{b}}$ & 3 & 4 & 5 & 6 & 7 & \\
\hline \multirow{2}{*}{$\begin{array}{l}2009 \\
(n=377)\end{array}$} & $30(8.0)$ & $156(41.4)$ & $42(11.1)$ & $59(15.6)$ & $25(6.6)$ & $0(0)$ & $65(17.2)$ & \multirow{2}{*}{$\begin{array}{c}0.17 \\
2009 \text { VS } 2010\end{array}$} \\
\hline & \multicolumn{2}{|c|}{$186(49.3)$} & \multicolumn{3}{|c|}{$126(33.4)$} & \multicolumn{2}{|c|}{$65(17.2)$} & \\
\hline \multirow{2}{*}{$\begin{array}{l}2010 \\
(n=96)\end{array}$} & $8(8.3)$ & $4(4.2)$ & $72(75.0)$ & $0(0)$ & $0(0)$ & $12(12.5)$ & o (o) & \multirow{2}{*}{$\begin{array}{c}<0.01 \\
2010 \text { VS } 2011\end{array}$} \\
\hline & \multicolumn{2}{|c|}{$12(12.5)$} & \multicolumn{3}{|c|}{$72(75.0)$} & \multicolumn{2}{|c|}{$12(12.5)$} & \\
\hline \multirow{2}{*}{$\begin{array}{l}2011 \\
(n=50)\end{array}$} & $8(16.0)$ & $1(2.0)$ & $17(34.0)$ & $0(0)$ & $1(2.0)$ & $23(46.0)$ & $\mathrm{o}(0)$ & 0.01 \\
\hline & \multicolumn{2}{|c|}{$9(18.0)$} & \multicolumn{3}{|c|}{$18(36.0)$} & \multicolumn{2}{|c|}{$23(46.0)$} & 2009 VS 2011 \\
\hline
\end{tabular}

a Determined using one-sided Mann-Whitney test.

${ }^{b}$ A serum pair for one episode of $Q$ fever was defined whenever these sera were collected within 90 days.

initial serum sample, and therefore in laboratory terms would be considered true positives. Follow-up serology was performed in four of these six cases: IgM phase II as well as IgG phase II antibodies against $C$. burnetii were not detected.

The proportion of the reconfirmed cases significantly decreased with the degree of certainty of the laboratory diagnosis and over the three-year period. Only a small minority of the laboratory-defined probable acute $Q$ fever cases in 2010 and 2011 were reconfirmed by the MHS and reported to the NCR (14/72 and 5/18 respectively). This proportion was even lower for the possible cases, where almost no cases were reported to the NCR (Table 4). In contrast, the probable and possible cases in 2009 were still mainly reconfirmed (100/126 and 54/65respectively). The differences were significant between 2009/1010 and 2009/2011 for all three laboratory interpretations. No differences were observed between 2010 and 2011.

\section{Discussion}

In this study, we showed that the continued use of a pre-outbreak case definition lead to over-reporting of acute Q fever to the MHS in the post-epidemic years. This was caused by the increasing seroprevalence in the population and the observed persistence of IgM antibody titres, both influencing the interpretation of serological test results. Therefore, a test result that was diagnostic for acute disease at the start of the outbreak became almost useless later on. For instance, the specificity of single IgM phase II positive results, in terms of inclusion in the NCR, was $83.1 \%$ in 2009 , whereas in 2010 and 2011, the specificity dropped to $0 \%$ and $13 \%$ respectively. According to national law, all notifications of laboratories and physicians should be investigated by the MHS infectious disease specialist in order to track down (new) sources, the principal reason for notification of $\mathrm{Q}$ fever. The over-reporting observed here in the course of a large outbreak does not aid such source finding.

Laboratory diagnosis of acute $\mathrm{Q}$ fever is quite complex. Culture techniques for $C$. burnetii are not available for routine practice, and therefore diagnosis relies on pathogen detection by PCR or serology or both. Although detection of $C$. burnetii DNA in serum by PCR is highly sensitive, it is also time-dependent, with a window for detection of approximately two weeks after onset of acute $Q$ fever symptoms [5]. Besides, not all diagnostic laboratories have C. burnetii PCR facilities. Therefore, serological tests will remain necessary in laboratory diagnosis of (acute) $Q$ fever. The variety of serological techniques and the implementation of new techniques throughout recent years make the diagnostic algorithms even more challenging. In our study period, 2009-2011, procedures changed three times: IFAT was introduced April 2009 for improvement of specificity, ELISA was implemented in June 2009 to increase the throughput time, and PCR was implemented in April 2010 inour laboratory to shorten the time to diagnosis. (Table 1 and Figure) Such changes are unavoidable during a large-scale outbreak: routine methods that were in place at the start of the outbreak were not suitable for large-scale use. Changing diagnostic methods in during an outbreak may influence the case definition used. Closer interaction between laboratory diagnosticians, epidemiologists and MHS infectious disease specialists is highly recommended: it will help unravel the notifications and focus investigation on real acute $Q$ fever cases.

The current laboratory criteria for notification contain confirmed laboratory cases (PCR positive or a four-fold 


\begin{tabular}{|c|c|c|c|c|c|c|}
\hline $\begin{array}{c}\text { Year } \\
\text { (number } \\
\text { of } \\
\text { cases) }\end{array}$ & $\begin{array}{c}\text { Total number } \\
\text { according to } \\
\text { laboratory } \\
\text { definition }\end{array}$ & $\begin{array}{c}\text { Reconfirmed by MHS } \\
\text { and reported to NCR } \\
\mathrm{n}(\%)\end{array}$ & $\begin{array}{c}\text { Total number } \\
\text { according to } \\
\text { laboratory } \\
\text { definition }\end{array}$ & $\begin{array}{c}\text { Reconfirmed by MHS } \\
\text { and reported to NCR } \\
\mathrm{n}(\%)\end{array}$ & $\begin{array}{c}\text { Total number } \\
\text { according to } \\
\text { laboratory } \\
\text { definition }\end{array}$ & $\begin{array}{c}\text { Reconfirmed by MHS } \\
\text { and reported to NCR } \\
n(\%)\end{array}$ \\
\hline $\begin{array}{c}2009 \\
(n=377)\end{array}$ & 186 & $184(98.9)$ & 126 & $100(79.4)$ & 65 & $54(83.1)$ \\
\hline $\begin{array}{c}2010 \\
(n=96)\end{array}$ & 12 & $7(58.3)$ & 72 & $14(19.4)$ & 12 & $0(0)$ \\
\hline $\begin{array}{c}2011 \\
(n=50)\end{array}$ & 9 & $4(44.4)$ & 18 & $5(27.8)$ & 23 & $3(13.0)$ \\
\hline
\end{tabular}

MHS: Municipal Health Services; NCR: national case register.

Percentages of notified cases in all three categories of laboratory interpretations (confirmed, probable and possible) were significantly different between 2009 vs 2010 and 2009 vs 2011, with a p value <0.001. The p value was determined using two-sided Fisher's exact test.

a Data from Laboratory for Pathology and Medical Microbiology (PAMM), Veldhoven.

increase in IgG phase II titre) and probable and possible cases (single serum IgM phase II positive) [11]. The last criterion, applied to patients with specific clinical symptoms, had a high positive predictive value in the epidemic year (2009). After the epidemic was successfully managed at the end of 2009, the incidence of acute Q fever fell drastically from 2010 onwards [12]. However, seroprevalence was high in the affected areas, reaching up to $20 \%$ of the population in some highly affected areas in the south of the Netherlands [13]. The number of laboratory requests remained high as the diagnostic triaging changed with increasing awareness. The total number of samples tested at our laboratory for acute $Q$ fever increased from 4,516 in 2009 to 5,138 in 2010 . Two years after the epidemic, the numbers decreased to 3,116 in 2011 and 2,946 in 2012. The group of patients subjected to diagnostic testing widened, thereby changing the positive predictive value of the same test outcome. Also, in the years after the epidemic, the indication for diagnostic testing changed from acute illness to (chronic) fatigue symptoms. Microbiologists can signal such changes but only if clinical information and other relevant background information is provided by the physician requesting the tests. However, this information is often lacking. As a consequence, the laboratory kept reporting IgM phase II positive patients to the MHS. IgG phase II and IgM phase II remain detectable for a long time after initial infection. Recently, it was shown that at least until 12 months after acute Q fever IgM phase II antibodies are detectable in the majority of the patients [7]. Since most of the acute $Q$ fever infections remain asymptomatic, IgM phase II in patients without classic symptoms represented mostly past infections instead of new acute cases in the post-epidemic period.
The need for more direct interaction between treating and notifying physicians and the laboratory was also illustrated by another finding: in our study, we found four PCR-positive cases (in 2010 and 2011) that were not included in the NCR. The reason for not reconfirming these cases was the aspecific clinical presentation together with the lack of serological response in follow-up sera from some of the cases, casting doubt on the performance of the diagnostic test. Positive $P C R$ without serological response weeks after initial symptom onset is highly unlikely. Although it has been suggested that antibody responses may be limited when antibiotic treatment is started early, this was not observed in a recent study [14]. Therefore, finding PCR-positive patients whose infection cannot be confirmed by serology suggests that they were due to false-positive PCR tests. PCR, which is highly sensitive, has always been prone to false-positive results, requiring strict protocols. Regretfully, despite these strict protocols, positives were still found that did not match the clinical picture, and again, with widening referral of patients, the positive predictive value of the same assay decreases. The combination of diagnostic serology and PCR can be problematic, as laboratory contamination may result in antigen preparations containing high levels of C. burnetii DNA [15]. After this phenomenon was reported, separate samples for serological and PCR tests were taken from patients, to reduce the potential of cross-contamination.

Although serological positive results do indicate infected patients, the inability to discriminate acute, chronic and past infections based on these criteria placed a lot of emphasis on the decision-making by the MHS. Notification of past infections does not support source finding, but will give MHS staff needless 
work. Therefore we recommend 'downsizing' the notification criteria, as was done in other infectious diseases $[16,17]$. For example, at the start of the influenza $\mathrm{A}\left(\mathrm{H}_{1} \mathrm{~N}_{1}\right)$ pdmog epidemic in 2009 and 2010, it was mandatory to report all new patients, but this was rapidly changed to hospitalized patients only. Notification was abandoned totally when influenza $A\left(\mathrm{H}_{1} \mathrm{~N}_{1}\right)$ pdmo9 became seasonal influenza [17].

The timing of change in notification criteria is rather arbitrary, but based on our retrospective data we conclude that the criteria could have been modified in 2010 for the $\mathrm{Q}$ fever-endemic areas in the Netherlands. We would recommend changing the laboratory case definition to rely on more specific testing as the incidence decreases and seroprevalence increases in a previously affected region by omitting IgM phase II positive sera and only report laboratory-confirmed cases. Whenever this is based on PCR positive sera, serological confirmation is recommended to monitor false positives due to contamination. Narrowing the notification rule to confirmed cases only is likely to lead to a more meaningful epicurve; notifications that are pending would no longer be taken into account. In order to keep a close eye on an epidemic, clinicians together with laboratories should closely follow up patients after a first positive result.

This study emphasises the importance of updating diagnostic criteria during an outbreak due to emerging pathogens. New notification rules in the aftermath of an epidemic are therefore necessary. As knowledge increases and diagnostic technology improves, definitions need to be changed to reflect those trends. We suggest a case definition that includes a degree of certainty (e.g. probable or confirmed) based on the different type of laboratory results.

\section{Acknowledgements}

No funding was obtained for this study. This study was performed during the EUPHEM fellowship of Giovanna Jaramillo Gutierrez.

\section{Conflict of interest}

None declared.

\section{Authors' contributions}

All authors were involved in the (i) conception and design and acquisition of data, or analysis and interpretation of data; (ii) drafting the article or revising it critically for important intellectual content; and (iii) final approval of the version to be published.
References

1. Maurin M, Raoult D. Q fever. ClinMicrobiol Rev. 1999;12(4):51853. PMid:10515901. PMCid:PMC88923.

2. Parker NR, Barralet JH,Bell AM. Q fever. Lancet. 2006;367(9511):679-88. http://dx.doi.org/10.1016/ S0140-6736(06)68266-4

3. Raoult D, Marrie T, Mege J. Natural history and pathophysiology of Q fever. Lancet Infect Dis. 2005;5(4):21926. http://dx.doi.org/10.1016/S1473-3099(05)70052-9

4. Wet publieke gezondheid. Wet van 9 oktober 2008 , houdende bepalingen over de zorg voor de publieke gezondheid (Wet publieke gezondheid).[Public Health Act. Law of 9 October 2008, containing provisions on the care of public health (Public Health Act).2008. Pub. L. No. BWBRo024705. Dutch. Available from: http://wetten.overheid.nl/BWBRo024705/ geldigheidsdatum_26-09-2013

5. Schneeberger PM, Hermans MH, van Hannen EJ, Schellekens JJ, Leenders AC, Wever PC. Real-time PCR with serum samples is indispensable for early diagnosis of acute $Q$ fever. Clin Vaccine Immunol. 2010;17(2):286-90. http://dx.doi.org/10.1128/ CVI.00454-09.

PMid:20032219. PMCid:PMC2815520.

6. Fournier PE, Raoult D. Comparison of PCR and serology assays for early diagnosis of acute Q fever. J Clin Microbiol. 2003;41(11):5094-8

http://dx.doi.org/10.1128/JCM.41.11.5094-5098.2003.

PMCid:PMC 262519

7. Wegdam-Blans MC, Wielders CC, Meekelenkamp J, Korbeeck JM, Herremans T, Tjhie HT, et al. Evaluation of commonly used serological tests for detection of Coxiella burnetii antibodies in well-defined acute and follow-up sera. Clin Vaccine Immunol. 2012;19(7):1110-5.

http:/dx.doi.org/10.1128/CVI.05581-11. PMid:22623653. PMCid:PMC3393374.

8. Wegdam-Blans MC, Nabuurs-Franssen MN, Horrevorts AM, Peeters MF, Schneeberger PM, Bijlmer HA. [Laboratory diagnosis of acute $Q$ fever]. Ned TijdschrGeneeskd. 2010;154:A2388. Dutch. PMid:20858325.

9. Delsing CE, Kullberg BJ, Bleeker-Rovers CP. Q fever in the Netherlands from 2007 to 2010. Neth J Med. 2010;68(12):382-7. PMid:21209463.

10. Dijkstra F, van der Hoek W, Wijers N, Schimmer B, Rietveld A, Wijkmans CJ, et al. The 2007-2010 Q fever epidemic in the Netherlands: characteristics of notified acute $Q$ fever patients and the association with dairy goat farming. FEMS Immunol Med Microbiol. 2012;64(1);3-12. http://dx.doi.org/10.1111/ j.1574-695X.2011.00876.x. PMid:22066649.

11. National Institute for Public Health and the Environment (RIVM). Q-koorts. [Q fever]. A78. LCl / Clb / RIVM directive infectious disease control. Bilthoven: RIVM; April 2010, last updated March 2011. Dutch. Available from: http://www.rivm. $\mathrm{n} /$ /dsresource?objectid=rivmp:6826\&type $=$ org \&disposition $=$ inline

12. van der Hoek W, Hogema BM, Dijkstra F, Rietveld A, Wijkmans CJ, Schneeberger PM, et al. Relation between Q fever notifications and Coxiella burentii infections during the 2009 outbreak in the Netherlands. Euro Surveill. 2012;17(3):pii=20058. Available from: http://www. eurosurveillance.org/ViewArticle.aspx?Articleld $=20058$

13. Kampschreur LM, Hagenaars JC, Wielders CC, Elsman $\mathrm{P}$, Lestrade PJ, Koning $\mathrm{OH}$, et al. Screening for Coxiellaburnetiiseroprevalence in chronic $Q$ fever high-risk groups reveals the magnitude of the Dutch $Q$ fever outbreak. Epidemiol Infect 2013;141:847-51.2012;13:1-5

14. Wielders CC, Kampschreur LM, Schneeberger PM, Jager $M M$, Hoepelman Al, Leenderes AC, et al. Early diagnosis and treatment of patients with symptomatic acute $Q$ Fever do not prohibit IgG antibody responses to Coxiella burnetii. Clin Vaccine Immunol. 2012;19(10):1661-6. http://dx.doi.org/10.1128/CVI.00322-12. PMid:22914364. PMCid:PMC3485890.

15. Tilburg JJ, Horrevorts AM, Peeters MF, Klaassen CH, Rossen JW. Identification by genotyping of a commercial antigen preparation as the source of a laboratory contamination with Coxiella burnetii and as an unexpected rich source of control DNA. J ClinMicrobiol. 2011;49(1):383-4. http:// dx.doi.org/10.1128/JCM.01491-10. PMid:20980565. PMCid:PMC3020417.

16. van 't Klooster TM, Wielders CC, Donker T, Isken L, Meijer A, van den Wijngaard CC, et al. Surveillance of hospitalisations for 2009 pandemic influenza $A\left(\mathrm{H}_{1} \mathrm{~N}_{1}\right)$ in the Netherlands, 5 June - 31 December 2009. Euro Surveill 2010;15(2): pii=19461. Available from: http://www.eurosurveillance.org/ViewArticle. aspx?Articleld $=19461$

17. Prince HE, Tobler LH, Yeh C, Gefter N, Custer B, Busch MP. Persistence of West Nile virus-specific antibodies in viremic blood donors. Clin Vaccine Immunol. 2007;14(9):1228-30. http://dx.doi.org/10.1128/CVI.00233-07. PMid:17652525. PMCid:PMC2043320. 